OPEN ACCESS

Edited by:

Umberto Volpe

Marche Polytechnic University, Italy

Reviewed by:

Reiji Yoshimura

University of Occupational and Environmental Health Japan, Japan Mandeep Bhullar,

Bhutta College of Education, India

*Correspondence:

Seockhoon Chung schung@amc.seoul.kr

Sooyeon Suh

alysuh@sungshin.ac.kr

tThese authors have contributed equally to this work

Specialty section:

This article was submitted to

Public Mental Health

a section of the journal

Frontiers in Psychiatry

Received: 21 May 2021

Accepted: 19 July 2021

Published: 11 August 2021

Citation:

Yoo S, Lee J, Ju G, Lee S, Suh S and Chung S (2021) The Schoolteachers' Version of the Stress and Anxiety to Viral Epidemics-9 (SAVE-9) Scale for Assessing Stress and Anxiety During the COVID-19 Pandemic.

Front. Psychiatry 12:712670. doi: 10.3389/fpsyt.2021.712670

\section{The Schoolteachers' Version of the Stress and Anxiety to Viral Epidemics-9 (SAVE-9) Scale for Assessing Stress and Anxiety During the COVID-19 Pandemic}

\author{
Soyoung Yoo ${ }^{1}$, Jihoon Lee ${ }^{2}$, Gawon $\mathrm{Ju}^{3}$, Sangha Lee ${ }^{4}$, Sooyeon Suh ${ }^{5 * t}$ and \\ Seockhoon Chung ${ }^{2 \times t}$
}

${ }^{1}$ Department of Convergence Medicine, University of Ulsan College of Medicine, Seoul, South Korea, ${ }^{2}$ Department of Psychiatry, Asan Medical Center, University of Ulsan College of Medicine, Seoul, South Korea, ${ }^{3}$ Department of Psychiatry, Chungbuk National University Hospital, Cheongju-si, South Korea, ${ }^{4}$ Department of Psychiatry, Ajou University School of Medicine, Suwon, South Korea, ${ }^{5}$ Department of Psychology, Sungshin Women's University, Seoul, South Korea

This study aimed to validate the schoolteachers' version of the Stress and Anxiety to Viral Epidemics-9 (SAVE-9) scale. This scale assessed the work-related stress and anxiety response of schoolteachers to the COVID-19 pandemic. A total of 400 schoolteachers participated in an online survey between March 4 and 15, 2021. The survey questionnaire included the schoolteachers' version of the SAVE-9, Patient Health Questionnaire-9 (PHQ-9), and Generalized Anxiety Disorders-7 (GAD-7) scales. A scree test and parallel analysis suggested a single-factor structure model for the schoolteachers' version of the SAVE-9 scale (real-data eigenvalue $=68.89$, 95th percentile of the random eigenvalues $=27.56$ ). The SAVE-9 scale showed good internal consistency (Cronbach's alpha $=$ 0.853 ) and good convergent validity with GAD-7 (rho $=0.545, p<0.001$ ) and PHQ-9 (rho $=0.434, p<0.001$ ) scale scores. This, schoolteachers' version of the SAVE-9 scale is a reliable and valid rating scale that can be applied to teachers in a pandemic situation.

Keywords: stress, psychological, teacher, COVID-19, anxiety

\section{INTRODUCTION}

In 2020, people experienced psychological issues such as depression, anxiety, and post-traumatic stress resulting from the coronavirus disease 2019 (COVID-19) pandemic and the subsequent economic crises. COVID-19-related lockdowns, social distancing, and quarantine disrupted their daily lives, business dealings, and interpersonal relationships (1). Although COVID-19 vaccines have been developed and available since December $2020^{1}, 185,291,530$ confirmed cases and $4,010,834$ deaths have been recorded globally. These are staggering and tragic numbers ${ }^{2}$.

\footnotetext{
${ }^{1}$ Available online at: https://ourworldindata.org/covid-vaccinations accessed on 2021, July, 12th.

${ }^{2}$ Available online at: https://covid19.who.int/ accessed on 2021, July, 12th.
} 
School environments were also severely disrupted and changed rapidly during the pandemic ${ }^{3}$. This resulted in schoolteachers experiencing high levels of stress or burnout (2, 3 ). When schools reopened, teachers who were not trained in infection control had the additional responsibility of preventing viral spread. This occurred by checking students' temperatures or rating their suspected symptoms. Moreover, they were required to direct students to wear masks and practice social distancing while at school. These tasks most likely imposed a severe burden on schoolteachers. Even when schools were closed owing to the lockdown, schoolteachers were required to adapt to a new educational environment and prepare for online education (4). They monitored students' academic abilities and supervised their progress while providing online classes. They also assisted in overcoming children's obstacles to learning (5) such as digital education inequity, absence of parents while students remained at home, and the lack of in-person teacher-studentparent relationships.

Reportedly, teachers had symptoms of stress, anxiety, and depression during the pandemic. This was especially evident among female teachers and those who had children (6). Their age, job stability, level of education, information sources, and level of apprehension also influenced their symptoms $(2,7)$. They experienced severe burnout (8), and their quality of life was hampered by work overload, feelings of uncertainty, and/or fear (9). Teachers played a key role in the educational environment during this pandemic. However, little research has been conducted focusing on their mental health, though they served as the forgotten frontline heroes of the COVID-19 pandemic (10). Further, to the best of our knowledge, there is no developed rating scale that can measure the anxiety and/or stress of teachers in response to specific viral epidemics. Therefore, we have attempted to develop the schoolteachers' version of the anxiety assessment scale using the SAVE-9 scale that has been developed for healthcare workers.

During the COVID-19 pandemic, healthcare workers, public workers, and schoolteachers cared for others at risk of COVID19. They played roles in the prevention of viral spread, experienced severe psychological distress, and endured workrelated burnout. They had to avoid becoming infected themselves and had to prevent the spread of viral infection to their family and co-workers. Therefore, it is important to develop epidemicspecific psychological assessment tools for the schoolteachers affected by the current pandemic. We recently developed a new rating scale, the Stress and Anxiety to Viral Epidemics-9 (SAVE-9) scale, to assess work-related stress and anxiety among healthcare workers in response to the COVID-19 pandemic (11). The scale was originally developed for frontline healthcare workers caring for patients during the COVID-19 pandemic. However, schoolteachers also were placed in a situation similar to that of healthcare workers. They cared for students and were also responsible for infection control in schools while being at risk of infection from students. Therefore, to address their mental health, it is important to assess the anxiety or work-related stress of schoolteachers during this pandemic situation. This study

${ }^{3}$ https://en.unesco.org/covid19/educationresponse accessed on 2021, July, 12th. explored the validity of the schoolteachers' version of the SAVE9 scale for assessing work-related stress among schoolteachers during the current COVID-19 pandemic.

\section{MATERIALS AND METHODS}

\section{Participants and Procedures}

We enrolled schoolteachers working in elementary, middle, and high schools in various regions in Korea. This study was conducted via an online survey administered by a professional online survey company, EMBRAIN ${ }^{4}$, during March 4-15, 2021. The surveys were completed anonymously. No personal information was gathered. The study protocol was approved and the requirement for written informed consent for participation was waived by the Institutional Review Board of Asan Medical Center (2021-0098). The participants voluntarily responded to this questionnaire. We used only the responses of participants who agreed to provide their data for statistical analysis.

\section{Symptom Assessment SAVE-9 Scale}

The main objective of this study was to develop and validate the schoolteachers' version of the SAVE-9 scale. The SAVE9 was originally developed to assess the mental health of healthcare workers' during the COVID-19 pandemic (11). The scale comprises nine items that considers two factors: (1) anxiety response to a viral epidemic and (2) work-related stress associated with a viral epidemic. To modify this SAVE-9 scale for schoolteachers, item 7 that stated "After this experience, do you think you will avoid treating patients with viral illnesses?” was changed to "Do you think you will avoid teaching children who have had viral illnesses." The participants were asked to rate their responses on a five-point Likert scale ranging from 0 (never) to 4 (always) $^{5}$.

\section{Patient Health Questionnaire-9}

The Patient Health Questionnaire-9 (PHQ-9) scale is a selfadministered questionnaire that is used to assess depressive symptoms. Respondents can rate their symptoms for each of the nine items on a three-point Likert scale $(0=$ not at all to $3=$ nearly every day). The total score of the PHQ-9 scale ranges from 0 to 27. The higher scores reflect more severe degrees of depressive symptoms (12). The present study defined the cut-off score for depression as $\geq 10$.

\section{Generalized Anxiety Disorder-7}

The Generalized Anxiety Disorder-7 (GAD-7) scale is a selfadministered questionnaire used to assess general anxiety. Respondents can rate their anxiety symptoms for each of the seven items on a three-point Likert scale $(0=$ not at all to 3 $=$ nearly every day). The total score of the GAD-7 scale ranges from 0 to 21 . The higher scores reflect more severe degrees of anxiety symptoms (13). The present study defined a score of 5 as the cut-off to identify cases with at least mild anxiety.

\footnotetext{
${ }^{4}$ http://www.embrain.com.

${ }^{5} \mathrm{http}: / /$ www.save-viralepidemic.net.
} 


\section{Statistical Analysis}

We conducted a principal component analysis (PCA) with varimax rotation to explore the factor structure of the schoolteachers' version of the SAVE-9 scale. Prior to conducting this analysis, we checked the normality assumption of each item based on its skewness and kurtosis, with an acceptable limit of range of \pm 2 (14). We also evaluated the data suitability and sampling adequacy using Kaiser-Meyer-Olkin values and Bartlett's tests of sphericity. A scree test and parallel analysis (1517), according to a minimum rank factor analysis (MRFA), with a 95th percentile threshold based on a polychoric correlations matrix was conducted to determine the number of factors to retain using the FACTOR 10.10.03. program (18). To define the factor structure, we compared the explained real-data eigenvalues with the 95th percentile of random eigenvalues. We decided where the real-data eigenvalues exceeded the 95th percentile of random eigenvalues. The reliability and internal consistency of the factors were examined using Cronbach's alpha and McDonald's Omega coefficients to verify the dimensionality of the schoolteacher's version of the SAVE-9 scale. To investigate the psychometric properties, independent $t$-tests were conducted using IBM SPSS Statistics for Windows, version 21.0. We assessed whether the SAVE-9 scale score differed significantly between groups based on sex (male vs. female), age (juniors vs. seniors), marital status (single vs. married), caring for infected students (yes vs. no), and being quarantined (yes vs. no). To determine the convergent validity, we performed a Spearman correlation analysis of the SAVE-9 scale score with age, years of employment, PHQ-9 scores, and GAD-7 scores, since the PHQ-9 and GAD-7 scales' scores did not show normal distributions. Finally, to define the appropriate cut-off score of the SAVE-9 scale consistent with the severity of the generalized anxiety (GAD-7 score), we conducted a receiver operating characteristic (ROC) analysis.

\section{RESULTS}

A total of 400 teachers participated in this study. They were from various regions in Korea, including Seoul $(N=78,19.5 \%)$, Pusan $(N=28,7.0 \%)$, Daegu $(N=28,7.0 \%)$, Daejeon $(N=8,2.0 \%)$, Gwangju $(N=10,2.5 \%)$, Chungcheong Province $(N=34,8.5 \%)$, Jeolla Province $(N=31,7.7 \%)$, Gyeongsang Province $(n=49$, $12.3 \%)$, Gangwon Province $(N=13,3.3 \%)$, and Jeju Province ( $N$ $=4,1.0 \%)$. Table 1 shows the demographic characteristics of the participants. Out of all the participants, $270(67.5 \%)$ were female and the others were male; 177 (44.3\%) were single; and $57(14.2 \%)$ had experienced or had been treated for depression, anxiety, or insomnia. Their mean duration of employment was $11.8 \pm 8.6$ years. Among the participants, $71(17.7 \%)$ had cared for students with confirmed COVID-19, 57 (14.2\%) had been quarantined due to COVID-19, and 1 (0.3\%) had developed COVID-19.

\section{Factor Structure of the Schoolteacher's Version of the SAVE-9 Scale}

Assessment of the normality assumption showed that the distributions of all nine items were within normal limits (Table 2). The data were suitable, and the sampling was
TABLE 1 | Demographic characteristics of the participants $(N=400)$.

\begin{tabular}{lc}
\hline Variables & $\begin{array}{c}\text { Mean } \pm \text { SD, } \\
\boldsymbol{N}(\%)\end{array}$ \\
\hline Teachers & \\
Elementary school & $140(35.0 \%)$ \\
Middle school & $130(32.5 \%)$ \\
High school & $130(32.5 \%)$ \\
Sex (female) & $270(67.5 \%)$ \\
Age (years) & \\
20-29 & $75(18.8 \%)$ \\
30-39 & $161(40.3 \%)$ \\
40-49 & $112(28.0 \%)$ \\
50-59 & $42(10.5 \%)$ \\
60-69 & $10(2.5 \%)$ \\
Marital status & \\
Single & $177(44.3 \%)$ \\
Married & $223(55.7 \%)$ \\
Years of employment & $11.8 \pm 8.6$ \\
COVID-19-related questions & \\
Did you care for children who have had viral & $71(17.7 \%)$ \\
illnesses? (Yes) & \\
Were you quarantined owing to exposure to & $57(14.2 \%)$ \\
COVID-19? (Yes) & \\
Were you positive for COVID-19? (Yes) & $1(0.3 \%)$ \\
Psychiatric history & \\
Have you ever experienced or were you treated & $57(14.2 \%)$ \\
for depression, anxiety, or insomnia? (Yes) & \\
Do you think you are currently depressed or & $44(11.0 \%)$ \\
anxious, or do you need help for your mood? & \\
\hline Yos) & \\
\hline
\end{tabular}

COVID-19, coronavirus disease 2019; SD, standard deviation.

adequate for PCA (Bartlett's test of sphericity, $p<0.001$; KaiserMeyer-Olkin $=0.897)$. To explore the factor structure of the schoolteacher's version of the SAVE-9 scale, a PCA was conducted, and a two-factor model was explored based on the eigenvalue plot (first factor eigenvalue $=4.337$, second factor eigenvalue $=1.054)$, which considered two factors: $(1)$ Factor I: anxiety regarding the viral epidemic (items 1, 2, 3, 4, and 8) and (2) Factor II: work-related stress associated with the viral epidemic (items 5, 6, 7, and 9) (Table 2). However, the results of the scree test and parallel analysis using MRFA extraction and polychoric correlation (that was conducted to identify the adequate number of factors for the scale) suggested a single-factor structure model (real-data eigenvalue $=68.89,95$ th percentile of random eigenvalue $=27.56$ ) for the schoolteacher's version of the SAVE-9 scale. Therefore, we adopted the singlestructure model.

\section{Reliability of the Scores and Evidence Based on Relationships With Other Variables}

The schoolteachers' version of the SAVE-9 scale showed good internal consistency (Cronbach's alpha $=0.853$ and McDonald's 
TABLE 2 | Factor structure of the schoolteachers' version of the SAVE-9 scale and factor loadings.

\begin{tabular}{|c|c|c|c|c|c|c|c|c|c|}
\hline \multirow[t]{2}{*}{ Items } & \multicolumn{5}{|c|}{ Responses } & \multirow[t]{2}{*}{ Mean \pm SD } & \multirow[t]{2}{*}{ Skewness } & \multirow[t]{2}{*}{ Kurtosis } & \multirow[t]{2}{*}{ Factor loading } \\
\hline & 0 & 1 & 2 & 3 & 4 & & & & \\
\hline $\begin{array}{l}\text { 1. Are you afraid the virus outbreak will continue } \\
\text { indefinitely? }\end{array}$ & $0.5 \%$ & $5.0 \%$ & $11.7 \%$ & $56.5 \%$ & $26.3 \%$ & $3.03 \pm 0.79$ & -0.903 & 1.187 & 0.509 \\
\hline $\begin{array}{l}\text { 2. Are you afraid your health will worsen because of the } \\
\text { virus? }\end{array}$ & $0.5 \%$ & $6.3 \%$ & $19.3 \%$ & $49.7 \%$ & $24.2 \%$ & $2.91 \pm 0.85$ & -0.637 & 0.194 & 0.626 \\
\hline 3. Are you worried that you might get infected? & $1.0 \%$ & $8.3 \%$ & $17.5 \%$ & $47.2 \%$ & $26.0 \%$ & $2.89 \pm 0.92$ & -0.732 & 0.159 & 0.708 \\
\hline $\begin{array}{l}\text { 4. Are you more sensitive toward minor physical } \\
\text { symptoms than usual? }\end{array}$ & $1.5 \%$ & $10.5 \%$ & $15.2 \%$ & $45.0 \%$ & $27.8 \%$ & $2.87 \pm 0.99$ & -0.786 & 0.069 & 0.681 \\
\hline $\begin{array}{l}\text { 5. Are you worried that others might avoid you even after } \\
\text { the infection risk has been minimized? }\end{array}$ & $9.8 \%$ & $26.5 \%$ & $24.7 \%$ & $24.5 \%$ & $14.5 \%$ & $2.08 \pm 1.22$ & 0.019 & -1.011 & 0.611 \\
\hline $\begin{array}{l}\text { 6. Do you feel skeptical about your job after going } \\
\text { through this experience? }\end{array}$ & $6.5 \%$ & $26.8 \%$ & $28.7 \%$ & $22.3 \%$ & $15.8 \%$ & $2.14 \pm 1.17$ & 0.090 & -0.928 & 0.695 \\
\hline $\begin{array}{l}\text { 7. Do you think you will avoid teaching children who have } \\
\text { had viral illnesses? }\end{array}$ & $8.3 \%$ & $21.5 \%$ & $24.2 \%$ & $35.5 \%$ & $10.5 \%$ & $2.19 \pm 1.14$ & -0.268 & -0.812 & 0.565 \\
\hline $\begin{array}{l}\text { 8. Do you worry your family or friends may become } \\
\text { infected because of you? }\end{array}$ & $2.0 \%$ & $6.8 \%$ & $20.5 \%$ & $43.8 \%$ & $27.0 \%$ & $2.87 \pm 0.95$ & -0.754 & 0.296 & 0.759 \\
\hline $\begin{array}{l}\text { 9. Do you think that your colleagues would have more } \\
\text { work to do due to your absence from a possible } \\
\text { quarantine and might blame you? }\end{array}$ & $4.8 \%$ & $10.7 \%$ & $19.8 \%$ & $43.8 \%$ & $21.0 \%$ & $2.66 \pm 1.07$ & -0.732 & -0.048 & 0.765 \\
\hline
\end{tabular}

SAVE-9, Stress and Anxiety to Viral Epidemics-9 items; SD, standard deviation.

$0=$ never; 1 = rarely; 2 = sometimes; $3=$ often; $4=$ always.

Omega $=0.850)$. The Spearman correlation coefficient showed significant correlations between the SAVE-9, GAD-7 (rho = 0.545, $p<0.001$ ), and PHQ-9 (rho $=0.434, p<0.001$ ) scale scores. The SAVE-9 scale score was significantly higher among healthcare workers who were rated as having generalized anxiety $\left[\mathrm{GAD}-7 \geq 10, t_{(398)}=10.155, p<0.001\right]$ and depression [PHQ$\left.9 \geq 10, t_{(398)}=7.896, p<0.001\right]$ than among those who did not. The SAVE-9 scale score was significantly higher for women than for men $\left[t_{(398)}=4.063, p<0.0001\right]$; however, it did not differ significantly according to marital status [single vs. married, $t_{(398)}=1.140, p=0.255$ ], age [junior 20-39 years vs. senior over 40 years, $\left.t_{(398)}=0.923, p=0.356\right]$, experience caring for infected students $\left[t_{(393)}=1.660, p=0.098\right]$, or experience being quarantined $\left[t_{(398)}=0.773, p=0.440\right]$.

\section{Cut-Off Score for the SAVE-9 Scale}

To explore the appropriate cut-off score of the SAVE-9 scale that corresponded to at least mild generalized anxiety, we conducted an ROC analysis using a GAD-7 scale score of 5. The ROC analysis revealed that the appropriate SAVE-9 cut-off score was $\geq 22$ (area under the curve $[\mathrm{AUC}]=0.729$, sensitivity $=0.79$, specificity $=0.54)$.

\section{DISCUSSION}

The results of this study showed that the schoolteacher's version of the SAVE-9 scale was reliable, with good internal consistency. We adopted the single-factor model of the SAVE9 scale. Moreover, the schoolteachers' version of the SAVE-9 scale showed good convergent validity with a pre-existing anxiety measurement tool (the GAD-7 scale). It exhibited a threshold score of 22 indicating at least mild generalized anxiety (GAD-7 scale score $\geq 5$ ).

A schoolteacher's role in this pandemic is like that of a healthcare worker. The teacher must care for his or her students just as the healthcare worker must care for his or her patients. For this sample of schoolteachers, we adopted a single-factor model based on the results of the parallel analysis, though PCA suggested a two-factor model. Parallel analysis was used to determine the number of components to retain from PCA (19). Parallel analysis is conducted based on the rationale of multiplying the total number of variable loadings by the significance level to provide an empirical estimate of the 95th percentile. We can also estimate by checking where the realdata eigenvalues exceeded the 95th percentile of the random eigenvalues. The schoolteachers' version of the SAVE-9 scale showed good internal consistency and convergent validity. In our previous sample of healthcare workers (11), items related to work-related stress (items 6, 7, and 9) were clustered separately, though items 5, 6, 7, and 9 were clustered in this sample in PCA. This difference may be due to differences in the working environments between healthcare workers and schoolteachers, the time frame of the survey, or the sampling variability.

The factor loading values of items 1 and 7 in this sample were 0.509 and 0.565 , respectively. Items are generally accepted when their factor loading values are $>0.6$ (20). However, items with values $>0.5$ may be acceptable if the consistency of the scale is good (21). Thus, we adopted all the items in the final model.

The appropriate cut-off score of the schoolteachers' version of the SAVE-9 scale was $\geq 22$ to indicate at least a mild degree of generalized anxiety (GAD-7 $\geq 5$ ) (AUC $=0.729$, sensitivity $=0.79$, specificity $=0.54)$. These results are consistent with those reported for the original SAVE-9 scale (11). We originally 
developed the SAVE-9 scale as a viral epidemic-specific anxiety rating scale especially for workers addressing or caring for people at high risk of infection in a pandemic. We intended to identify a mild degree of anxiety response to the viral epidemic to screen for healthcare workers requiring psychological support during the current pandemic. Similarly, we defined a cut-off score for the schoolteachers' version of the SAVE-9 scale. It corresponded to a GAD-7 score of $\geq 5$ (mild degree) to screen for schoolteachers with at least mild anxiety regarding the current viral epidemic. Thus, the schoolteachers' version of the SAVE-9 scale can be applied as it showed good validity in the educational setting.

This study had several limitations. First, the survey was conducted via an anonymous online survey as it was not easy to interview the participants face-to-face during the current pandemic situation. Though we used the services of a professional survey company, the nature of the survey may have introduced errors. Second, the survey was conducted about 1 year after the outbreak. Thus, the teachers might have adapted to their situations, developed online education skills, and cared for students during the pandemic in 2020. This may influence the validity of the schoolteachers' version of the SAVE-9 scale. In this study, we could not collect the data of participants' race, income, education, or socioeconomic status. The status of the pandemic in Korea might be different from that in other countries in which the pandemic is severe. The school or teaching system, the availability of remote learning, or cultural differences related to education should also be considered. Therefore, the results of this study cannot be generalized to samples from other countries. Finally, as the SAVE-9 scale was originally developed for COVID19 frontline healthcare workers, there are some issues with applying this scale to schoolteachers. However, the SAVE-9 scale focuses on individual anxiety or stress regarding a viral epidemic rather than on clinical practice. Therefore, it can be applied to a schoolteacher that cares for students.

In conclusion, like the SAVE-9 scale for healthcare workers, the teachers' version of the SAVE-9 scale is a reliable and valid rating scale for assessing the anxiety and work-related stress

\section{REFERENCES}

1. Brooks SK, Webster RK, Smith LE, Woodland L, Wessely S, Greenberg N, et al. The psychological impact of quarantine and how to reduce it: rapid review of the evidence. Lancet. (2020) 395:912-20. doi: 10.1016/S0140-6736(20)3 0460-8

2. Ozamiz-Etxebarria N, Berasategi Santxo N, Idoiaga Mondragon N, Dosil Santamaría M. The psychological state of teachers during the COVID-19 crisis: the challenge of returning to face-to-face teaching. Front Psychol. (2021) 11:620718. doi: 10.3389/fpsyg.2020.620718

3. Stachteas P, Stachteas C. The psychological impact of the COVID19 pandemic on secondary school teachers. Psychiatriki. (2020) 31:293301. doi: $10.22365 /$ jpsych.2020.314.293

4. Van Lancker W, Parolin Z. COVID-19, school closures, and child poverty: a social crisis in the making. Lancet Public Health. (2020) 5:e243e4. doi: 10.1016/S2468-2667(20)30084-0

5. Gore J, Fray L, Miller A, Harris J, Taggart W. The impact of COVID-19 on student learning in New South Wales primary schools: an empirical study. Aust Educ Res. (2021). doi: 10.1007/s13384-021-00436-w. [Epub ahead of print]. of schoolteachers. During the current pandemic, we hope that the SAVE-9 scale will be used to measure the work-related stress and anxiety response of schoolteachers who teach and care for students. We also hope that this scale will assist in the development of support systems that will decrease their psychological distress.

\section{DATA AVAILABILITY STATEMENT}

The raw data supporting the conclusions of this article will be made available by the authors, without undue reservation.

\section{ETHICS STATEMENT}

The study protocol was approved and the requirement for written informed consent for participation was waived by the Institutional Review Board of Asan Medical Center (2021-0098). Written informed consent for participation was not required for this study in accordance with the national legislation and the institutional requirements.

\section{AUTHOR CONTRIBUTIONS}

SC and SS developed the study concept. Testing and data collection were performed by JL, SL, and GJ. Data analysis and interpretation were performed by SC, SS, GJ, and SL. SY and SC drafted the paper. All authors contributed to the study design, provided critical revisions, and approved the final version of the paper for submission.

\section{FUNDING}

This work was supported under the Framework of International Cooperation Program managed by the National Research Foundation of Korea (FY2020K2A9A1A01094956).

6. Santamaria MD, Mondragon NI, Santxo NB, Ozamiz-Etxebarria N. Teacher stress, anxiety and depression at the beginning of the academic year during the COVID-19 pandemic. Glob Ment Health. (2021) 8:e14. doi: 10.1017/gmh.2021.14

7. Li Q, Miao Y, Zeng X, Tarimo CS, Wu C, Wu J. Prevalence and factors for anxiety during the coronavirus disease 2019 (COVID-19) epidemic among the teachers in China. J Affect Disord. (2020) 277:1538. doi: 10.1016/j.jad.2020.08.017

8. Amri A, Abidli Z, Elhamzaoui M, Bouzaboul M, Rabea Z, Ahami AOT. Assessment of burnout among primary teachers in confinement during the COVID-19 period in morocco: case of the Kenitra. Pan Afr Med J. (2020) 35:92. doi: 10.11604/pamj.supp.2020.35.2.24345

9. Lizana PA, Vega-Fernadez G, Gomez-Bruton A, Leyton B, Lera L. Impact of the COVID-19 pandemic on teacher quality of life: a Longitudinal study from before and during the health crisis. Int J Environ Res Public Health. (2021) 18:3764. doi: 10.3390/ijerph18073764

10. Beames JR, Christensen H, Werner-Seidler A. School teachers: the forgotten frontline workers of covid-19. Australas Psychiatry. (2021). doi: 10.1177/10398562211006145. [Epub ahead of print]. 
11. Chung S, Kim HJ, Ahn MH, Yeo S, Lee J, Kim K, et al. Development of the stress and anxiety to viral epidemics-9 (SAVE-9) scale for assessing workrelated stress and anxiety in healthcare workers in response to COVID-19. PsyArXiv [Preprint]. (2020). doi: 10.31234/osf.io/a52b4

12. Kroenke $\mathrm{K}$, Spitzer RL, Williams JB. The PHQ-9: validity of a brief depression severity measure. J Gen Intern Med. (2001) 16:606-13. doi: 10.1046/j.1525-1497.2001.016009606.x

13. Spitzer RL, Kroenke K, Williams JB, Lowe B. A brief measure for assessing generalized anxiety disorder: the GAD-7. Arch Intern Med. (2006) 166:10927. doi: 10.1001/archinte.166.10.1092

14. Gravetter F, Wallnau L. Essentials of Statistics for the Behavioral Sciences, 8th Ed. Wadsworth, OH; Belmont, CA: Wadsworth (2014).

15. Horn J. A rationale and test for the number of factors in factor analysis. Psychometricka. (1965) 30:179-85. doi: 10.1007/BF02289447

16. Glorfeld LW. An improvement on horn's parallel analysis methodology for selecting the correct number of factors to retain. Educ Psychol Meas. (1995) 55:377-93. doi: 10.1177/0013164495055003002

17. Timmerman ME, Lorenzo-Seva U. Dimensionality assessment of ordered polytomous items with parallel analysis. Psychol Methods. (2011) 16:20920. doi: $10.1037 / \mathrm{a} 0023353$

18. Lorenzo-Seva U, Ferrando PJ. FACTOR: a computer program to fit the exploratory factor analysis model. Behav Res Methods. (2006) 38:8891. doi: 10.3758/BF03192753

19. Franklin SB, Gibson DJ, Robertson PA, Pohlmann JT, Fralish JS. Parallel analysis: a method for determining significant principal components. J Veg Sci. (1995) 6:99-106. doi: 10.2307/32 36261

20. Zainudin A. Structural Equation Modeling using aMOS Graphic. Shah Alam: UiTM Press (2012).

21. Hair JF, Babin AH, Money P. Essentials of Business Research Methods. Hoboken, NJ: John Wiley \& Sons (2003).

Conflict of Interest: The authors declare that the research was conducted in the absence of any commercial or financial relationships that could be construed as a potential conflict of interest.

Publisher's Note: All claims expressed in this article are solely those of the authors and do not necessarily represent those of their affiliated organizations, or those of the publisher, the editors and the reviewers. Any product that may be evaluated in this article, or claim that may be made by its manufacturer, is not guaranteed or endorsed by the publisher.

Copyright (C) 2021 Yoo, Lee, Ju, Lee, Suh and Chung. This is an open-access article distributed under the terms of the Creative Commons Attribution License (CC BY). The use, distribution or reproduction in other forums is permitted, provided the original author(s) and the copyright owner(s) are credited and that the original publication in this journal is cited, in accordance with accepted academic practice. No use, distribution or reproduction is permitted which does not comply with these terms. 